\title{
Audit of Physicians' Adherence to a Preprinted Order Set for Community-Acquired Pneumonia
}

\author{
Curt T Fowkes, Carol Gee, Tammy Bluemink, Dana Cole, Barbara L Falkner, and Abu A Hamour
}

\begin{abstract}
Background: Community-acquired pneumonia is the seventh leading cause of death in Canada. Previous studies have shown reductions in both mortality rate and length of hospital stay with the use of guidelineconcordant empiric therapy and standardized preprinted orders.

Objectives: The primary objective was to determine adherence to the preprinted order for community-acquired pneumonia at the University Hospital of Northern British Columbia (UHNBC). The study also had the following secondary objectives: to assess the appropriateness of prescribing of levofloxacin in relation to institutional recommendations; to determine adherence with recent guidelines from the Infectious Diseases Society of America (IDSA) and the American Thoracic Society (ATS) for the treatment of community-acquired pneumonia; and to determine allcause mortality, duration of IV antibiotic therapy, and length of stay for the various regimens reviewed.
\end{abstract}

Methods: A retrospective observational chart review was conducted of patients with community-acquired pneumonia who were admitted between November 2007 and February 2008. Exclusion criteria were designed to eliminate patients who did not have this condition. Descriptive statistics were used to assess adherence with the preprinted order. Secondary outcomes were analyzed with the Pearson $\chi^{2}$ test, $t$ tests, and analysis of variance.

Results: In total, the charts for 113 patients were reviewed, and 58 patients were included in the study. The preprinted order for communityacquired pneumonia was used for 25 (43\%) of the 58 patients; however, for only 4 (7\%) of these admissions were all sections of the preprinted order used correctly. No statistically significant differences in length of stay were found for any of the antibiotic combinations assessed. However, the proportion of patients treated according to the IDSA-ATS guidelines was significantly greater when the preprinted order was used $(p=0.012)$. In addition, use of the preprinted order encouraged assessment of the patient's pneumococcal vaccination status (9 [25\%] of 25 patients versus 3 [9\%] of 33 patients) and utilization of the pneumonia severity index (13 [52\%] of 25 patients versus 0 [0\%] of 33 patients).

Conclusion: The preprinted order for community-acquired pneumonia at UHNBC was not being utilized to its fullest. However, when it was used, it increased guideline-concordant empiric therapy and encouraged assessment of patients' pneumococcal vaccination status and pneumonia severity index.

\section{RÉSUMÉ}

Contexte : La pneumonie extra-hospitalière est la septième principale cause de mortalité au Canada. Des études ont montré que le taux de mortalité et la durée de l'hospitalisation diminuaient avec l'emploi d'un traitement empirique conforme aux lignes directrices et l'utilisation d'ordonnances préimprimées standardisées.

Objectifs : Le principal objectif était de déterminer le taux d'observance à une ordonnance préimprimée actuellement utilisée au University Hospital of Northern British Columbia pour la prise en charge de la pneumonie extra-hospitalière. L'étude comportait aussi les objectifs secondaires suivants : évaluer la pertinence de la prescription de la lévofloxacine relativement aux recommandations de l'établissement; déterminer l'observance des récentes lignes directrices de l'Infectious Diseases Society of America (IDSA) et de l'American Thoracic Society (ATS) dans la prise en charge de la pneumonie extra-hospitalière; et rendre compte des décès toutes causes confondues, de la durée de l'antibiothérapie intraveineuse et de la durée de l'hospitalisation pour les divers schémas examinés.

Méthodes : On a effectué une analyse d'observation rétrospective des dossiers médicaux des patients atteints de pneumonie extra-hospitalière qui ont été hospitalisés entre novembre 2007 et février 2008. Les critères d'exclusion ont été conçus pour éliminer les cas non atteints de cette maladie. Des statistiques descriptives ont été calculées pour évaluer l'observance de l'ordonnance préimprimée. Les paramètres d'évaluation secondaires ont été analysés à l'aide du test du chi carré de Pearson, des tests de t et de l'analyse de variance.

Résultats : Au total, les dossiers médicaux de 113 patients ont été analysés et 58 inclus dans l'étude. L'ordonnance préimprimée pour la prise en charge de la pneumonie extra-hospitalière a été utilisée chez 25 ( $43 \%$ ) des 58 patients; cependant, toutes les sections de l'ordonnance préimprimée n’ont été remplies correctement que pour seulement 4 (7 \%) de ces patients hospitalisés. Aucune différence statistiquement significative n'a été observée dans la durée de l'hospitalisation pour toutes les combinaisons d'antibiotiques analysées. En revanche, la proportion de patients traités conformément aux lignes directrices de l'IDSA-ATS était considérablement plus élevée lorsque l'ordonnance préimprimée était utilisée $(\mathrm{p}=0,012)$. De plus, le recours à celle-ci a favorisé l'évaluation de l'état vaccinal antipneumococcique des patients (9 [25\%] des 25 patients contre 3 [9\%] des 33 patients) et l'utilisation de l'indice de gravité de la pneumonie (13 [52\%] des 25 patients contre 0 [0\%] des 33 patients).

Conclusion : Lordonnance préimprimée pour la prise en charge de la pneumonie extra-hospitalière n'était pas utilisée à son plein potentiel au 
Key words: pneumonia, guidelines, levofloxacin, vaccination, pneumonia severity index, microbial susceptibility

Can J Hosp Pharm 2010;63(4):289-294
University Hospital of Northern British Columbia. Cependant, lorsqu'elle était utilisée, elle a accru l'observance du traitement empirique aux lignes directrices et favorisé l'évaluation de l'état vaccinal antipneumococcique des patients et l'utilisation de l'indice de gravité de la pneumonie.

Mots clés : pneumonie, lignes directrices, lévofloxacine, vaccination, indice de gravité de la pneumonie, sensibilité microbienne

[Traduction par l'éditeur]

\section{INTRODUCTION}

Ctatistics Canada has reported pneumonia as the seventh Sleading cause of death in Canada, ${ }^{1}$ with the number of deaths due to pneumonia peaking in January. ${ }^{2}$ These statistics provide compelling reasons to ensure that patients with community-acquired pneumonia are treated effectively, to minimize the mortality rate. In addition to decreasing morbidity and mortality, effective treatment is important in minimizing the financial burden on the health care system that is associated with admission to hospital for community-acquired pneumonia.

Previous studies have shown that strict adherence to clinical practice guidelines (e.g., the 2007 consensus guidelines of the Infectious Diseases Society of America [IDSA] and the American Thoracic Society [ATS $]^{3}$ ) decreases mortality and can reduce the length of the hospital stay for patients with community-acquired pneumonia. ${ }^{4.5}$ Specifically, Frei and oth$\mathrm{ers}^{4}$ reported a reduction in average length of stay of 1.2 days $(p<0.01)$ and an absolute decrease in mortality of $4 \%$ $(p<0.01)$ with guideline-concordant empiric therapy relative to therapy not concordant with guidelines. In another study, utilization of a guideline-based physician order set decreased the odds ratio for death from 0.92 to $0.86 .^{5}$

The preprinted order for community-acquired pneumonia at the University Hospital of Northern British Columbia (UHNBC), which is available in print form on all wards and in the emergency department, includes levofloxacin as a treatment option for patients who have at least 1 of 3 specific indications: documented allergy to penicillin, failure of prior B-lactam therapy, or known minimum inhibitory concentration of penicillin for Streptococcus pneumoniae of $4 \mathrm{mg} / \mathrm{L}$ or greater. In the year preceding the study reported here, pharmacists and physicians suspected an increase in inappropriate prescribing of levofloxacin (as defined by the specific criteria on the preprinted order, as outlined above) and observed a decrease in the susceptibility of S. pneumonia to levofloxacin, from 95\% (for June 2007 to May 2008) to $81 \%$ (for June 2008 to May 2009). Additionally, reports of lack of attention to the indications for treatment with the levofloxacin regimen on the preprinted order raised questions as to whether other sections (specifically, those related to the pneumonia severity index and assessment of pneumococcal vaccination status) were being used appropriately. These concerns warranted assessment of prescribing habits at this institution.

The primary objective of this study was to evaluate the treatment of patients with community-acquired pneumonia who were admitted to UHNBC to determine adherence to the preprinted order for treatment of this condition. The secondary objectives were to assess the appropriateness of prescribing of levofloxacin therapy in relation to the institution's recommendations; to determine adherence with recommended treatment of community-acquired pneumonia as outlined in the recent IDSA-ATS guidelines; and to determine all-cause mortality, duration of IV antibiotic therapy, and length of stay for the various regimens reviewed.

The hypothesis was that the preprinted order for communityacquired pneumonia at UHNBC was not being utilized to its fullest extent and that levofloxacin was being prescribed more frequently than would be the case if the specific criteria of the preprinted order were being followed.

\section{METHODS}

\section{Study Design and Participants}

For this retrospective, observational chart review, patients at least 18 years of age who had been admitted between November 1, 2007, and February 29, 2008, and for whom a diagnosis of pneumonia was recorded on the discharge summary were considered for inclusion.

Patients were included if treatment for pneumonia had been initiated during the hospital stay and if none of the exclusion criteria (which targeted patients without community-acquired pneumonia) were present.

The following exclusion criteria were intended to exclude patients without true community-acquired pneumonia: readmission within 7 days of a previous admission, dialysis therapy (which requires multiple admissions), residence in a nursing home, and diagnosis of pneumonia more than $72 \mathrm{~h}$ after admission. Patients with cystic fibrosis, HIV/AIDS, tuberculosis, and aspiration pneumonia, as well as those undergoing active chemotherapy and those who had undergone transplantation, 
were also excluded, because treatment for any of these conditions might necessitate deviations from standard management of community-acquired pneumonia.

\section{Data Collection}

Patients were identified with the help of the medical records department, which used codes from the International Statistical Classification of Diseases and Related Health Problems, 10th revision, to identify patients who had been admitted with pneumonia; patients less than 18 years old were excluded. One of the investigators (C.T.F.) reviewed each patient record for exclusion criteria and collected pertinent data for eligible patients.

The appropriateness of levofloxacin use in relation to the institution's recommendations was evaluated by estimating the information available to the prescriber at the time the antibiotic or antibiotics were prescribed. Because of concerns that the information available in each health care record would be insufficient to calculate the pneumonia severity index for patients for whom the preprinted order had not been used, the CURB65 score (based on Confusion, Urea nitrogen, Respiratory rate, Blood pressure, and 65 years of age and older ${ }^{6}$ ) was calculated for all patients, to allow comparison of severity of illness between the 2 populations (with and without use of preprinted orders). In addition, it was anticipated that prescribers who had not used the preprinted order would not have documented the pneumonia severity index separately.

\section{Statistical Analysis}

An a priori power analysis was not performed, nor were additional statistics defined a priori, as the initial plan was to use descriptive statistics to reveal prescribing patterns. However, after the study was initiated, the investigators decided that it would be worthwhile to perform a statistical analysis to properly assess the effect of the preprinted order.

The primary outcome of adherence to the preprinted order was reported with descriptive statistics, as planned. Statistical analyses not defined a priori included a 2-way contingency table analysis using Pearson $\chi^{2}$ analysis to evaluate whether there was a statistically significant relationship between use of the preprinted order and use of medications as indicated. In addition, the $\chi^{2}$ for independence was used to investigate the relationship between use of the preprinted order and adherence to clinical practice guidelines.

Additional tests not defined a priori were an independentsample $t$ test comparing length of stay between patients who received treatment according to the preprinted order and patients whose treatment did not involve use of the preprinted order. A one-way analysis of variance (ANOVA) was used to compare the effect of 3 drug regimens on patients' recovery (as measured by length of stay). Finally, an independent-sample $t$ test was conducted to compare the length of stay between patients who received levofloxacin intravenously and those who received this drug orally.

\section{RESULTS}

A total of 113 charts were reviewed from the list of potential participants generated by the medical records department. Of the 113 patients, 58 met the inclusion criteria without any exclusion criteria. The other 55 charts were excluded for the following reasons: coding error or no clear diagnosis of pneumonia $(n=16)$, readmission $(n=9)$, onset of pneumonia more than $72 \mathrm{~h}$ after admission $(n=7)$, admission outside the defined study dates $(n=6)$, aspiration pneumonia $(n=4)$, concurrent HIV $(n=4)$, admission history incomplete $(n=3)$, residence in a nursing home $(n=3)$, active chemotherapy $(n=2)$, and concurrent tuberculosis $(n=1)$.

The preprinted order was used for 25 (43\%) of the 58 patients admitted for community-acquired pneumonia (Table 1). Even when the preprinted order was used, the 3 sections of the form requiring physician input (antibiotic selection, assessment of pneumococcal vaccination status, and pneumonia severity index) were seldom completed correctly: for only $4(16 \%)$ of these 25 patients were all 3 sections of the form completed appropriately, and for 1 patient (4\%) errors or omissions meant that none of these sections was completed appropriately. Of the patients for whom the preprinted order was used, $9(36 \%)$ had documentation of the assessment of pneumococcal vaccination status, and 13 (52\%) had a record of the pneumonia severity index score. In contrast, of the patients for whom the preprinted order was not used, 3 (9\%) had documentation of assessment of pneumococcal vaccination status, and none had a record of the pneumonia severity index score. Of the patients treated without use of the preprinted order, 21 (64\%) received treatment in accordance with the IDSA-ATS guidelines. This proportion was significantly greater among the patients for whom the preprinted order was used (23 [92\%] of 25 patients) $(p=0.012)$.

Among the patients treated with levofloxacin, this drug was prescribed inappropriately, as defined by the institution's recommendations on the preprinted order, for $71 \%$ (10/14) of the patients for whom the preprinted order was not used and $50 \%(4 / 8)$ of those for whom the preprinted order was used $(p=0.32)$. More specifically, levofloxacin was given as monotherapy, as recommended by the preprinted order, to only $16(72 \%)$ of the 22 patients who received this drug. Overall, criteria for the use of levofloxacin at the UHNBC were not met in $64 \%$ of cases (14/22).

The duration of antibiotic therapy, length of stay, mortality rate, and standardized severity-of-illness scores (i.e., CURB-65 severity score) are outlined in Table 2 . There were no statisti- 
Table 1. Characteristics of 58 Patients with Community-Acquired Pneumonia

\begin{tabular}{lrlrl} 
& \multicolumn{3}{c}{ Use of Preprinted Orders; No. (\%) of Patients* } \\
\cline { 2 - 5 } Characteristic & \multicolumn{2}{c}{ Yes $(\boldsymbol{n}=\mathbf{2 5})$} & \multicolumn{2}{c}{ No $(\boldsymbol{n}=\mathbf{3 3})$} \\
\hline Sex (male) & 14 & $(56)$ & 13 & $(39)$ \\
Age, mean and range (years) & 62 & $(36-91)$ & 68 & $(23-85)$ \\
Allergy to penicillin & 5 & $(20)$ & 6 & $(18)$ \\
Comorbidities & & & & \\
Asthma & 3 & $(12)$ & 5 & $(15)$ \\
Chronic obstructive pulmonary disease & 11 & $(44)$ & 9 & $(27)$ \\
Smoker & 12 & $(48)$ & 7 & $(21)$ \\
Ex-smoker & 4 & $(16)$ & 11 & $(33)$ \\
Lung cancer & 1 & $(4)$ & 4 & $(12)$ \\
Other malignancy & 1 & $(4)$ & 1 & $(3)$ \\
Exacerbation of chronic heart failure & 9 & $(36)$ & 5 & $(15)$ \\
Previous use of antibiotic & & & & \\
B-Lactam & 1 & $(4)$ & 0 & $(0)$ \\
Other & 4 & $(16)$ & 5 & $(15)$ \\
\hline
\end{tabular}

*Except where indicated otherwise.

Table 2. Outcomes for 58 Patients with Community-Acquired Pneumonia

\begin{tabular}{lcccrr} 
Type of Therapy & $\begin{array}{c}\text { Duration of } \\
\text { Antibiotic Use, } \\
\text { Mean (days) }\end{array}$ & $\begin{array}{c}\text { Duration of IV } \\
\text { Therapy, Mean and } \\
\text { Range (days) }\end{array}$ & $\begin{array}{c}\text { Length of Stay, } \\
\text { Mean and } \\
\text { Range (days) }\end{array}$ & $\begin{array}{c}\text { Mortality Rate } \\
\text { (No. and \%) }\end{array}$ & $\begin{array}{c}\text { CURB-65, } \\
\text { Mean and Range }\end{array}$ \\
\hline Preprinted order used $(n=25)$ & 5.9 & $3.2(0-6)$ & $6.3(1-17)$ & 0 & $1.8(1-5)$ \\
Preprinted order not used $(n=33)$ & 5.5 & $4.0(0-12)$ & $5.9(1-12)$ & 5 & $(15)$ \\
Levofloxacin monotherapy $(n=16)$ & 4.6 & $1.7(0-6)$ & $4.9(3-11)$ & 0 & $2.2(0-5)$ \\
IV $(n=8)$ & 4.3 & $3.4(2-6)$ & $5.0(3-11)$ & 0 & $2.4(1-4)$ \\
PO $(n=8)$ & 4.9 & NA & $4.9(3-9)$ & 0 & $2.4(1-4)$ \\
B-Lactam + macrolide $(n=27)$ & 5.3 & $4.2(1-8)$ & $5.5(1-16)$ & 2 & $(7)$ \\
Any other combination $(n=15)$ & 7.3 & $4.9(0-12)$ & $7.6(2-17)$ & $3(1-4)$ & $1.9(0-4)$ \\
\hline
\end{tabular}

cally significant differences in length of stay among the regimens. Five deaths occurred among patients for whom the preprinted order was not used. Two of these deaths were due to respiratory failure associated with comorbid metastatic lung cancer. The 3 remaining deaths were due to severe sepsis (cultures positive for Streptococcus pneumoniae in 2 cases and for Haemophilus influenzae in the third case). All of these organisms were susceptible to the initial empiric therapy (cephalosporin and a macrolide).

\section{DISCUSSION}

Overall, the preprinted order for community-acquired pneumonia was used for fewer than half (43\%) of the patients included in the study, and all sections of the form were used correctly for only $7 \%$ of the patients. From these results, it appears that the preprinted order was less likely to be used for those with more severe pneumonia (mean CURB-65 score 1.8 versus 2.2 for patients with and without use of preprinted order, respectively) and for those with more comorbidities (Table 1). This indicates a lack of confidence in the suitability of the preprinted order for patients who are very sick. In addition, the preprinted order may need to be modified to include treatment recommendations that take into consideration other factors such as the patient's age and comorbidities.

As expected, levofloxacin was prescribed inappropriately (as monotherapy when no indication for this drug was present or in combination with any other antibiotic) more often than not (64\% overall). Use of the preprinted order appeared to decrease the inappropriate prescribing of levofloxacin, but this difference did not reach statistical significance. It should be noted that as currently defined on the preprinted order, some of the indications for use of levofloxacin are difficult to assess for initial empiric therapy. For example, the prescribing physician will usually not know at the time of initial assessment if the patient is infected with a penicillin-resistant organism. To address this problem, it may be necessary to include an instruction to step down to ß-lactam therapy if levofloxacin has been initiated and culture results indicate that this step-down would be feasible. The availability of data through the provincial PharmaNet system in British Columbia means that a physician should know if the patient has previously experienced failure of $ß$-lactam therapy. 
In a previous study comparing levofloxacin with the combination of ß-lactam and macrolide, the length of stay was shorter with levofloxacin than with the combination therapy ( 5 days versus 6 days, respectively) $(p=0.01) .^{7}$ In addition, another previous study of community-acquired pneumonia reported a shorter length of stay (by up to 2 days) with early switching (3 days after admission) from IV to orally administered antibiotics relative to a 7-day course of IV antibiotics (which was the standard for the authors' institution). ${ }^{8}$ In the study reported here, use of any combination of antibiotics not suggested in the preprinted order was associated with greater length of stay: 4.9 and 5.5 days for levofloxacin and B-lactam + macrolide, respectively, versus 7.6 days for any combination not in the preprinted order. However, this difference was not statistically significant $(p=0.07)$. The lack of a significant difference could be due to any of several factors, including (but not limited to) the small sample size (power analysis not performed), the retrospective nature of the study, and the ad hoc statistical analysis. In addition, we found no difference in length of stay between IV and oral administration of levofloxacin ( $p=0.61$ ) (Table 2). The 5 deaths among patients for whom the preprinted order was not used were likely not related to the lack of use of the preprinted order or to the antibiotic selection, given the causes of death and the susceptibilities of organisms cultured.

Despite the limitations of small sample size and no a priori definition of statistics, concordance with guidelines was significantly greater when the preprinted order was used, as has been reported previously. ${ }^{3,4}$ Unlike previous studies, however, there was no change in length of stay with use of the preprinted order. This may have been a result of the small sample size, and follow-up research is warranted.

Irrespective of the potential decrease in length of stay and mortality rate when a preprinted order is used, there are additional potential benefits of this tool. When the preprinted order was used, patients in this study were 3 times more likely to have their pneumococcal vaccination status formally assessed and documented in the medical chart. Use of this vaccine has been shown to decrease admission rates for communityacquired pneumonia (hazard ratio $=0.66$ ). ${ }^{9}$ Also, for $52 \%$ of the patients for whom the preprinted order was used, the severity of pneumonia was assessed objectively with the pneumonia severity index; in contrast, only $3 \%$ of those for whom the preprinted order was not used had such an assessment. Use of an objective system for scoring severity of illness (such as the pneumonia severity index or the CURB-65) has been shown to decrease unnecessary admissions of patients who can be managed as outpatients. ${ }^{10,11}$ Therefore, the potential impact of using preprinted orders to free up hospital resources is great.

The retrospective design of this study limited the data collection to what was documented in the original patient care record. Furthermore, because the statistical analyses performed were not defined a priori, there may have been some inadvertent bias in the selection of analytical tests.

The small sample size may have led to a type 2 statistical error (failure to reject the null hypothesis even though the null hypothesis was actually false), specifically in terms of the difference in inappropriate prescribing of levofloxacin between the 2 groups.

This institution would benefit from futher research to determine why the preprinted order for community-acquired pneumonia is not being utilized to its fullest. In addition, it should be determined why physicians who do use the preprinted order are not completing all 3 sections correctly. A survey of practising physicians, to gather feedback about the existing preprinted order and suggestions of ways to improve it, may be helpful to identify areas for improvement. The preprinted order could then be updated, and a future study of similar design undertaken to assess any improvement in adherence to all sections of the form.

\section{CONCLUSIONS}

At the UHNBC, the preprinted order for communityacquired pneumonia was not being utilized to the desired extent during the study period. When the form was used, it resulted in significantly better adherence to IDSA-ATS guidelines for empiric therapy. Conversely, when the form was not used, clinical aspects of a patient's therapy for communityacquired pneumonia were missed. Increased use of the preprinted order would likely result in more effective triage and more consistent assessment of vaccination history before discharge. Further research is needed to discover the reasons why the preprinted order is not being used, and modification of the current preprinted order is warranted to increase adherence and to maximize the benefits of the preprinted order.

\section{References}

1. Vital statistics. Ottawa (ON): Statistics Canada; [cited 2010 Jun 23]. Available from: http://www40.statcan.gc.ca/101/cst01/hlth36a-eng.htm

2. Trudeau R. Monthly and daily patterns of death. Health Rep 1997; 9(1):43-50.

3. Mandell LA, Wunderink RG, Anzueto A, Bartlett JG, Campbell GD, Dean NC, et al. Infectious Diseases Society of America/American Thoracic Society consensus guidelines on the management of communityacquired pneumonia in adults. Clin Infect Dis 2007;44 Suppl 2;S27-S72.

4. Frei CR, Restrepo MI, Mortensen EM, Burgess DS. Impact of guidelineconcordant empiric antibiotic therapy in community-acquired pneumonia. Am J Med 2006;119(10):865-871.

5. Dean NC, Bateman KA, Donnelly SM, Silver MP, Snow GL, Hale D. Improved clinical outcomes with utilization of a community-acquired pneumonia guideline. Chest 2006;130(3):794-799.

6. Ebell MH. Outpatient vs. inpatient treatment of community acquired pneumonia. Fam Pract Manag 2006;13(4):41-44.

7. Lodise TP, Kwa A, Cosler L, Gupta R, Smith RP. Comparison of betalactam and macrolide combination therapy versus fluroquinolone monotherapy in hospitalized Veterans Affairs patients with community- 
acquired pneumonia. Antimicrob Agents Chemother 2007;51(11): 3977-3982.

8. Oosterheert JJ, Bonten MJM, Schneider MME, Buskens E, Lammers JWJ, Hustinx WMN, et al. Effectiveness of early switch from intravenous to oral antibiotics in severe community acquired pneumonia: multicentre randomised trial. BMJ 2006;333(7580):1193.

9. Huss A, Scott P, Stuck AE, Trotter C, Egger M et al. Efficacy of pneumococcal vaccinations in adults: a meta-analysis. CMAJ 2009;180(1):48-58.

10. Aujesky D, Fine MJ. The pneumonia severity index: a decade after the initial derivation and validation. Clin Infect Dis 2008;47 Suppl 3:S133-S139.

11. Aronsky D, Dean NC. Admission decision for pneumonia: a validation study of the CURB-65 criteria [abstract]. Chest 2004;126 Suppl 4:738S.

Curt T Fowkes, BSC(Pharm), ACPR, is the Regional Drug Use Evaluation Pharmacist for Northern Health and a Clinical Pharmacist (Intensive Care Unit/Cardiac Care Unit) at the University Hospital of Northern British Columbia, Prince George, British Columbia.

Carol Gee, BSC(Pharm), is a Clinical Pharmacist at the University Hospital of Northern British Columbia, Prince George, British Columbia

Tammy Bluemink, BSc(Pharm), is a Clinical Pharmacist in the Regional Cancer Care Unit at the University Hospital of Northern British Columbia, Prince George, British Columbia.

Dana Cole, BSC(Pharm), ACPR, PharmD, is a Regional Director of Pharmacy Services for Northern Health and Assistant Professor of Pharmacology, University of Northern British Columbia, Prince George, British Columbia.
Barbara L Falkner, BScPharm, PharmD, is a Clinical Pharmacist in the Clinical Teaching Unit and the Intensive Care Unit/Cardiac Care Unit, University Hospital of Northern British Columbia, Prince George, British Columbia.

Abu A Hamour, MBBS, MSC, FRCP(Edin), FRCP, is an infectious diseases specialist in internal medicine at the University Hospital of Northern British Columbia, Prince George, British Columbia, and is also a Clinical Assistant Professor with the University of British Columbia, Vancouver, British Columbia.

\section{Address correspondence to:}

Curt T Fowkes

Pharmacy Department

University Hospital of Northern British Columbia

1475 Edmonton Street

Prince George BC V2M 1S2

e-mail: curt.fowkes@northernhealth.ca

\section{Acknowledgement}

We thank James Chan, BA(Hons), MA, Research and Evaluation Coordinator for Northern Health, for performing the statistical analysis.

\section{ON THE FRONT COVER}

\section{English Bay, Vancouver, British Columbia}

As the pink cloak of twilight descends, the boats head out into English Bay, in anticipation of the spectacular fireworks that will soon ensue. This photograph was taken from Vanier Park in Vancouver,

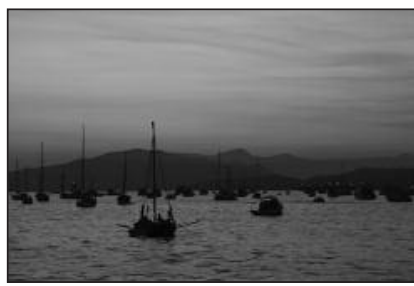

British Columbia, on a beautiful summer night in 2009, immediately before the annual HSBC Celebration of Light.
The photographer was CSHP member Elaine Chong, who has a newly acquired penchant for Canon digital SLR cameras and L-lenses. 